J Am Chem Soc. 2019 September 18; 141(37): 14570-14575. doi:10.1021/jacs.9b08662.

\title{
Catalytic Deuterium Incorporation within Metabolically Stable $\beta$ - Amino C-H Bonds of Drug Molecules
}

\author{
Yejin Chang ${ }^{\ddagger}$, Ahmet Yesilcimen ${ }^{\ddagger}$, Min Cao, Yuyang Zhang, Bochao Zhang, Jessica Z. \\ Chan, Masayuki Wasa* \\ Department of Chemistry, Merkert Chemistry Center, Boston College, Chestnut Hill, \\ Massachusetts 02467, United States
}

\begin{abstract}
An efficient deuteration process of $\beta$-amino $\mathrm{C}-\mathrm{H}$ bonds in various $N$-alkylamine-based pharmaceutical compounds has been developed. Catalytic reactions begin with the action of Lewis acidic $\mathrm{B}\left(\mathrm{C}_{6} \mathrm{~F}_{5}\right)_{3}$ and Brønsted basic $N$-alkylamine, converting a drug molecule into the corresponding enamine. The acid/base catalysts also promote the dedeuteration of acetone- $d_{6}$ to afford a deuterated ammonium ion. Ensuing deuteration of the enamine then leads to the formation of $\beta$-deuterated bioactive amines with up to $99 \%$ deuterium incorporation.
\end{abstract}

\section{Graphical Abstract}
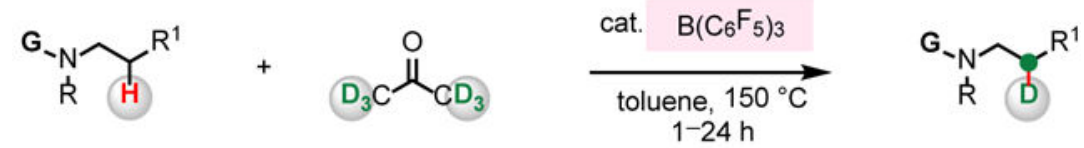

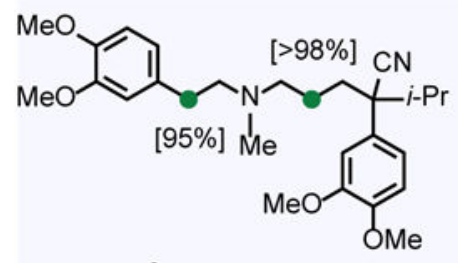

$\left[{ }^{2} \mathrm{H}\right]$-verapamil

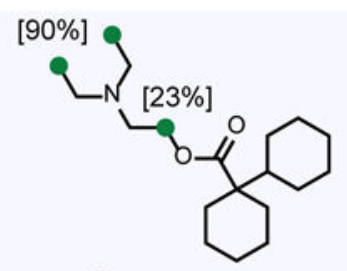

$\left[{ }^{2} \mathrm{H}\right]$-dicyclomine

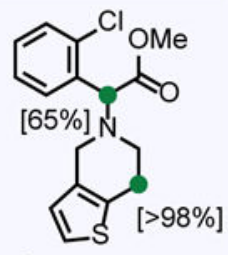

$\left[{ }^{2} \mathrm{H}\right]$-clopidogrel

Deuterium-labeled pharmaceuticals are pivotal diagnostic tools in research aimed at determination of the corresponding biological outcomes and metabolites. ${ }^{1-6}$ Drugs containing $\mathrm{C}-\mathrm{D}$ bonds have been prepared through multistep synthesis involving the reduction of unsaturated or halogenated intermediates. ${ }^{3}$ However, innovations in organometal-catalyzed $\mathrm{C}-\mathrm{H}$ activation have enabled direct hydrogen isotope exchange (HIE) at $\mathrm{C}-\mathrm{H}$ bonds for deuterium. ${ }^{4-6}$ In particular, HIE reaction targeting $\mathrm{C}\left(\mathrm{sp}^{3}\right)-\mathrm{H}$ bonds of pharmaceuticals that contain an $\mathrm{N}$-alkylamine unit is in high demand because these

*Corresponding Author wasa@bc.edu.

¥Y. C. and A. Y. contributed equally to this paper.

The authors declare no competing financial interest.

Supporting Information Available: Experimental procedures and spectral data for all new compounds (PDF). This material is available free of charge via the Internet at http://pubs.acs.org. 
entities constitute over $50 \%$ of the top-selling commercial drugs. ${ }^{7}$ The state-of-the-art processes include Beller's $\boldsymbol{a}$ - and $\beta$-amino $\mathrm{C}-\mathrm{H}$ deuteration of metoclopramide (A1) and two other structurally related drug molecules promoted by Ru-based Shvo catalyst (Figure 1A). ${ }^{5}$ MacMillan's photoredox-mediated $\boldsymbol{a}$-deuteration and $\boldsymbol{a}$-tritiation represents a notable strategy for isotopic labelling of a range of $N$-alkylamine-based drugs (Figure 1B). ${ }^{6}$ Still, development of methods for regioselective deuteration of poorly reactive $\beta$-amino $\mathrm{C}\left(\mathrm{sp}^{3}\right)$ $-\mathrm{H}$ bonds of drugs containing Lewis acid- and base-sensitive functional groups with an inexpensive deuterium source and promoted by non-precious metal-based catalysts is a significant challenge. ${ }^{8,9}$ Regioselective deuteration of metabolically stable $\beta$-amino $\mathrm{C}-\mathrm{H}$ bonds (vs more labile $a$-amino $\mathrm{C}-\mathrm{H}$ bonds) is particularly attractive as it minimizes the loss of the label due to exchange. ${ }^{1-3}$

We began by contemplating a possible way to design a method for deuteration of biologically active compounds that contain an $\mathrm{N}$-alkylamine unit (1) with readily available acetone- $d_{6} \mathbf{2}$ as a source of deuterium (Figure 1C). We considered utilizing a combination of Lewis acid and Brønsted base catalysts that would function cooperatively. ${ }^{10-12} \mathrm{We}$ envisioned that $\mathrm{B}\left(\mathrm{C}_{6} \mathrm{~F}_{5}\right)_{3}$ could receive a hydride from an amine (1), generating a borohydride and an iminium ion (I). ${ }^{13-19}$ Subsequently, a Brønsted basic amine catalyst would deprotonate I, furnishing enamine $\mathbf{I I} .{ }^{13-16}$ Concurrently, the $N$-alkylamine could dedeuterate $\mathrm{B}\left(\mathrm{C}_{6} \mathrm{~F}_{5}\right)_{3}$-activated acetone- $d_{6} \mathbf{2}$, generating an enolate and a deuterated ammonium ion (III). ${ }^{20}$ Ensuing deuteration (IV) of the enamine II by III gives an iminium ion; subsequent borohydride reduction would afford $\beta$-deuterated product 3 . Here, we report the development of a catalyst system for $\beta$-amino $\mathrm{C}-\mathrm{H}$ deuteration of bioactive amines.

We first set out to identify a desirable combination of catalysts. We probed the ability of $\mathrm{B}\left(\mathrm{C}_{6} \mathrm{~F}_{5}\right)_{3}$ and various Brønsted bases to catalyze the reaction between verapamil 1a and acetone- $d_{6} \mathbf{2}$ (6.8 equivalent), generating $\mathbf{3 a}$ (Table 1). Treatment of $\mathbf{1 a}$ and $\mathbf{2}$ with $5.0 \mathrm{~mol} \%$ $\mathrm{B}\left(\mathrm{C}_{6} \mathrm{~F}_{5}\right)_{3}$ and $10 \mathrm{~mol}_{\%} \mathrm{NEt}_{3}, \mathrm{NBn}_{3}$, or 1,2,2, 6,6-pentamethylpiperidine (PMP) afforded 3a in $>90 \%$ yield (toluene, $125^{\circ} \mathrm{C}, 1 \mathrm{~h}$ ); $16-34 \%$ of $\beta$-amino $\mathrm{C}-\mathrm{H}$ bonds were converted to $\mathrm{C}-\mathrm{D}$ bonds (entries 1-3). With more Brønsted basic 1,8-diazabicyclo[5.4.0]undec-7-ene (DBU), no labeling was observed (entry 4). When the transformation was performed without a Brønsted base co-catalyst, $\mathbf{3 a}$ was generated with $35 \%$ and $21 \%$ deuterium incorporation (entry 5), suggesting that $N$-alkylamines 1a and/or 3a can promote deprotonation of the iminium ion (I, Figure 1C; $\mathrm{NR}_{3}=\mathbf{1 a}$ and/or 3a). Deuterium incorporation diminished to $<10 \%$ with $5.0 \mathrm{~mol} \%$ of $\mathrm{B}\left(\mathrm{C}_{6} \mathrm{~F}_{5}\right)_{3}$ and reaction temperature of $100{ }^{\circ} \mathrm{C}$ (entry 6 ), but when the reaction mixture was heated at $150{ }^{\circ} \mathrm{C}, \mathbf{3 a}$ was obtained with $>80 \%$ labeling (entry 7). With $10 \mathrm{~mol} \% \mathrm{~B}\left(\mathrm{C}_{6} \mathrm{~F}_{5}\right)_{3}$ there was only minor improvement (entry 8, 88\% and $92 \%$ ). However, by reacting 1a with two batches of $5.0 \mathrm{~mol} \%$ of $\mathrm{B}\left(\mathrm{C}_{6} \mathrm{~F}_{5}\right)_{3}$ and 2 (6.8 equivalent), we were able to obtain 3a with $>95 \%$ deuterium incorporation (entry 9). There was no labeling without $\mathrm{B}\left(\mathrm{C}_{6} \mathrm{~F}_{5}\right)_{3}$ or when the less hindered $\mathrm{BF}_{3}$ or the less Lewis acidic $\mathrm{BPh}_{3}$ were used (entries 10-12). These findings support the notion that strongly acidic $\mathrm{B}\left(\mathrm{C}_{6} \mathrm{~F}_{5}\right)_{3}$ together with sterically demanding and electron-rich $N$-alkylamine constitute the most effective combination. ${ }^{10}$

Acyclic $\beta$-amino $\mathrm{C}-\mathrm{H}$ bonds in a number of pharmaceuticals $(\mathbf{1 a}-\mathbf{1 j})$ underwent efficient deuteration (Table 2). This protocol was found to be compatible with compounds that 
contain an array of Lewis acid-sensitive functional groups. In addition to the $N$-alkylamine units of $\mathbf{1 a}-\mathbf{1 j}$, cyano $(\mathbf{1 a})$, ester $(\mathbf{1 b})$, amide $(\mathbf{1 d}, \mathbf{1 e}, \mathbf{1 f})$ and ketone $(\mathbf{1 j})$ were tolerated to give the deuteration products $\mathbf{3 a}-\mathbf{3 j}$ in 77 to $>95 \%$ yield after purification by silica gel chromatography. Labeling took place with high regioselectivity for $\beta$-amino $\mathrm{C}-\mathrm{H}$ bonds. In addition, drug molecules that possess acidic $a$-carbonyl $\mathrm{C}-\mathrm{H}$ bonds also underwent efficient deuteration (3d, 3j) based on analysis of ${ }^{1} \mathrm{H}$ NMR spectra of unpurified mixtures. Nonetheless, in case of $\mathbf{3 d}, \boldsymbol{a}$-carbonyl $\mathrm{C}-\mathrm{D}$ bonds of indolin-2-one underwent $\mathrm{H}-\mathrm{D}$ exchange during purification.

For substrates that possess electronically and sterically disparate $\beta$-amino $\mathrm{C}-\mathrm{H}$ bonds (1a, $\mathbf{1 b}, \mathbf{1 c}, \mathbf{1 d}, \mathbf{1 g}, \mathbf{1 j})$, deuterium labeling occurred at varying levels. With verapamil 1a, benzylic $\mathrm{C} 2-\mathrm{H}$ and non-benzylic $\mathrm{C} 4-\mathrm{H}$ bonds were converted to $\mathrm{C}-\mathrm{D}$ bonds in $>95 \%$, but deuteration of non-benzylic $\mathrm{C} 4-\mathrm{H}$ bonds was more efficient (Table 1, entries 5-9). With dicyclomine $\mathbf{1 b}$, while $90 \%$ of $\mathrm{C} 2-\mathrm{H}$ bonds of $N$-ethyl groups was deuterated, only $23 \%$ of $\mathrm{C} 1-\mathrm{H}$ bonds adjacent to an ester group were converted to $\mathrm{C}-\mathrm{D}$ bonds. Similar reactivity was observed with clomiphene 1c: $90 \%$ of $\mathrm{C}^{2}$ '- $\mathrm{H}$ bonds were converted into $\mathrm{C} 2$ ' -D bonds, but $15 \%$ of $a$-aryloxy $\mathrm{C} 1-\mathrm{H}$ bonds were deuterated. Ropinirole $1 \mathrm{~d}$ was labeled at benzylic $\mathrm{C} 1-\mathrm{H}$ bonds (63\%), and $\mathrm{C} 2-\mathrm{H}$ bonds of $N$-propyl group (86\%).

Although the catalytic protocol tolerates an array of functional groups, isotopic labeling was more efficient with substrates bearing a protecting group. For instance, $80 \%$ of $\beta-\mathrm{C}-\mathrm{H}$ bonds of lidocaine 1e, which possesses acidic amide $\mathrm{N}-\mathrm{H}$ bonds, was converted to $\mathrm{C}-\mathrm{D}$ bonds to give 3e. However, deuteration of $N$-benzyl-protected lidocaine $1 \mathbf{f}$ proceeded more efficiently to afford $\mathbf{3 f}$ with $96 \%$ d-incorporation; in addition, deuteration of $a$-carbonyl $\mathrm{C}-\mathrm{H}$ bonds was also observed (9\%). Cinacalcet $\mathbf{1 g}$ containing a secondary amine moiety was a compatible substrate to provide $3 \mathrm{~g}$ (63\% [C2] and $8 \%$ [C2']), and $\mathrm{N}$-benzyl-protected cinacalcet $3 \mathrm{~h}$ was obtained with $>98 \%$ of $\beta$-amino $\mathrm{C} 2-\mathrm{H}$ bonds selectively converted into $\mathrm{C}-\mathrm{D}$ bonds. With less sterically hindered secondary amines nortriptyline $\mathbf{1 i}$ and propafenone $\mathbf{1 j}$, their reaction with acetone- $d_{6}$ may inhibit labeling. However, with an $N$ benzhydryl group installed, $\mathbf{3 i}$ and $\mathbf{3 j}$ could be readily generated. Silyl protection of the secondary alcohol proved to be effective in the case of propafenone $\mathbf{1 j}$, giving $\mathbf{3} \mathbf{j}$ (76\% [C2] and $0 \%$ at more sterically hindered [C2']).

Next, we investigated possible labeling of various pharmaceuticals that contain cyclic $\beta$ amino $\mathrm{C}-\mathrm{H}$ bonds (Table $3 ; \mathbf{1 k}-\mathbf{1 s}$ ). A variety of Lewis acid-sensitive heterocycles such as piperidine (1k-1q), 1,4-diazepane (1r), piperazine (1s), thiophene (1k, 1l), indanone (1m), benzodioxole (1o, 1p), benzothiophene (1q), as well as benzoimidazole (1r) were tolerated to give the corresponding deuteration products in 85 to $>95 \%$ yield. With clopidogrel $\mathbf{1 k}$, prasugrel 1l, and donepezil 1m, both $\beta$-amino $\mathrm{C}-\mathrm{H}$ bonds and enolizable $a$-carbonyl $\mathrm{C}-\mathrm{H}$ bonds underwent efficient deuteration to give $\mathbf{3 k}-\mathbf{3 m}$, but acidic $a$-keto $\mathrm{C}-\mathrm{D}$ bond of $\mathbf{3 1}$ was converted to $\mathrm{C}-\mathrm{H}$ bond during purification. Less acidic $a$-amide $\mathrm{C}-\mathrm{H}$ bond of bupivacaine 1n was not deuterated. With bupivacaine $1 \mathbf{n}$ and raloxifene 1q that contain acyclic and cyclic $\beta$-amino $\mathrm{C}-\mathrm{H}$ bonds, labeling of the cyclic $\mathrm{C}-\mathrm{H}$ bond was more efficient ( $>90 \%$ vs $\_9 \%$ for the acyclic C-H). $N$-Benzyl (1o) and $N$-benzhydryl (1p)protected paroxetine gave $\mathbf{3 o}$ and $\mathbf{3 p}$, respectively. The level of labeling for the more 
hindered 3p (94\%) was superior to 3o (76\%). Furthermore, deuteration of the C5-H bond occurred selectively, while the tertiary $\mathrm{C} 3-\mathrm{H}$ bond remained intact. Deuteration of emedastine $1 \mathbf{r}$ was found to take place at $\mathrm{C} 2-\mathrm{H}(33 \%)$ and $\mathrm{C} 6-\mathrm{H}(60 \%)$ bonds. All eight $\mathrm{C}-\mathrm{H}$ bonds of piperazine ring of $O$-TBS-protected dropropizine $1 \mathrm{~s}$ underwent deuteration to afford 3s (>86\%). Using this protocol, $a$-amino $\mathrm{C}-\mathrm{H}$ deuteration occurred only when these bonds were also alpha to a carbonyl group (3f) or beta to a $\mathrm{N}$ atom (3s).

The method is scalable. Treatment of $1.4 \mathrm{~g}(3.0 \mathrm{mmol})$ of verapamil $1 \mathrm{a}$ with $5.0 \mathrm{~mol} \%$ $\mathrm{B}\left(\mathrm{C}_{6} \mathrm{~F}_{5}\right)_{3}, 20 \mathrm{mmol}$ of acetone- $d_{6}$ (toluene, $12 \mathrm{~h}, 150{ }^{\circ} \mathrm{C}$ ), followed by filtration through a pad of silica gel and repeating the aforementioned procedure afforded $\mathbf{3 a}$ in $95 \%$ yield (2.9 mmol, $1.3 \mathrm{~g}$ ) and $>93 \%$ deuterium incorporation (Scheme 1).

To summarize, we have designed an efficient and regioselective deuterium labeling of $\beta$ amino $\mathrm{C}-\mathrm{H}$ bonds in various bioactive molecules, provided that sufficient steric congestion is present around the reacting amine. By implementing the cooperative action of $\mathrm{B}\left(\mathrm{C}_{6} \mathrm{~F}_{5}\right)_{3}$ and $N$-alkylamine catalyst system, we show that it is possible to convert an $N$-alkylaminebased pharmaceutical compound to the corresponding enamine, and that the same catalyst system can generate a labeling agent from acetone- $d_{6}$. The principles outlined herein, entailing conversion of amine containing drugs into enamines and its reaction with in situ generated electrophilic partner, provide a new rational framework for late-stage modification of a drug candidate. Studies along these lines are in progress.

\section{Supplementary Material}

Refer to Web version on PubMed Central for supplementary material.

\section{Acknowledgements.}

Financial support was provided by the NIH (GM-128695), the Sloan Foundation, and Boston College. We thank Professor Amir H. Hoveyda (Boston College) for helpful discussions.

\section{References}

(1). (a)For selected reviews on hydrogen isotope exchange, see: Atzrodt J; Derdau V; Fey T; Zimmermann J The Renaissance of H/D Exchange. Angew. Chem., Int. Ed 2007, 46, 7744-7765. (b)Harbeson SL; Tung RD Deuterium Medicinal Chemistry: A New Approach to Drug Discovery and Development. MedChem News 2014, 2, 8-22.(c)Atzrodt J; Derdau V; Kerr WJ; Reid M Deuterium- and Tritium-Labelled Compounds: Applications in the Life Sciences. Angew. Chem., Int. Ed 2018, 57, 1758-1784.(d)Atzrodt J; Derdau V; Kerr WJ; Reid M C-H Functionalisation for Hydrogen Isotope Exchange. Angew. Chem., Int. Ed 2018, 57, 3022-3047. (e)Pirali T; Serafini M; Cargnin S; Genazzani AA Applications of Deuterium in Medicinal Chemistry. J. Med. Chem 2019, 62, 5276-5297. [PubMed: 30640460]

(2) (a). Penner N; Klunk LJ; Prakash C Human Radiolabeled Mass Balance Studies: Objectives, Utilities and Limitations. Biopharm. Drug Dispos 2009, 30, 185-203. [PubMed: 19544285] (b)Miyoshi S; Mitsuoka K; Nishimura SA in Radioisotopes-Applications in Bio-Medical Science, Singh N, Ed.; InTech-Open Access Publisher, 2011; Chapter 5.

(3). (a)For the multistep synthesis of hydrogen isotope-labeled drugs, see: Maltais F; Jung YC; Chen M; Tanoury J; Perni RB; Mani N; Laitinen L; Huang H; Liao S; Gao H; Tsao H; Block E; Ma C; Shawgo RS; Town C; Brummel CL; Howe D; Pazhanisamy S; Raybuck S; Namchuk M; Bennani YL In Vitro and In Vivo Isotope Effect with Hepatitis C Protease Inhibitors: Enhanced Plasma Exposure of Deuterated Telaprevir versus Telaprevir in Rats. J. Med. Chem 2009, 52, 7993-8001. 
[PubMed: 19894743] (b)Allen PH; Hickey MJ; Kingston LP; Wilkinson DJ Metal-catalysed isotopic exchange labelling: 30 years of experience in pharmaceutical R\&D. J. Labelled Comp. Radiopharm 2010, 53, 731-738.(c)Lockey WJS; McEwen A; Cooke R Tritium: a coming of age for drug discovery and development ADME Studies. J. Labelled Comp. Radiopharm 2012, 55, 235-257.(d)Elmore CS; Bragg RA Isotope chemistry; a useful tool in the drug discovery arsenal. Bioorg. Med. Chem. Lett 2015, 25, 167-171. [PubMed: 25499878]

(4). (a)For organometal-catalyzed hydrogen isotope exchange reactions, see: Pieters G; Taglang C; Bonnefille E; Gutmann T; Puente C; Berthet J-C; Dugave C; Chaudret B; Rousseau B Regioselective and Stereospecific Deuteration of Bioactive Aza Compounds by the Use of Ruthenium Nanoparticles. Angew. Chem., Int. Ed 2014, 53, 230-234.(b)Taglang C; MartinezPrieto LM; del Rosal I; Maron L; Poteau R; Philippot K; Chaudret B; Perato S; Lone AS; Puente C; Dugave C; Rousseau B; Pieters G Enantiospecific C-H Activation Using Ruthenium Nanocatalyst. Angew. Chem., Int. Ed 2015, 54, 10474-10477.(c)Yu RP; Hesk D; Rivera N; Pelczer I; Chirik PJ Iron-catalyzed tritiation of pharmaceuticals. Nature 2016, 529, 195-199. [PubMed: 26762456] (d)Hale LVA; Szymczak NK Stereoretentive Deuteration of $a$-Chiral Amines with $\mathrm{D}_{2} \mathrm{O}$. J. Am. Chem. Soc 2016, 138, 13489-13492. [PubMed: 27709928] (e)Chatterjee B; Krishnakumar V; Gunanathan C Selective $a$-Deuteration of Amines and Amino Acids using $\mathrm{D}_{2} \mathrm{O}$. Org. Lett 2016, 18, 5892-5895. [PubMed: 27805814] (f)Sawama Y; Nakano A; Matsuda T; Kawajiri T; Yamada T; Sajiki H H-D Exchange Deuteration of Arenes at Room Temperature. Organic Process Research \& Development, 2019, 23, 648-653. KERR, Derdau, Kerr.

(5). Neubert L; Michalik D; Bahn S; Imm S; Neumann H; Atzrodt J; Derdau V; Holla W; Beller M Ruthenium-Catalyzed Selective $a, \beta$-Deuteration of Bioactive Amines. J. Am. Chem. Soc 2012, 134, 12239-12244. [PubMed: 22702889]

(6). Loh YY; Nagao K; Hoover AJ; Hesk D; Rivera NR; Colletti SL; Davies IW; MacMillan DWC Photoredox-catalyzed deuteration and tritiation of pharmaceutical compounds. Science 2017, 358, 1182-1187. [PubMed: 29123019]

(7). McGrath NA; Brichacek M; Njardarson JT A Graphical Journey of Innovative Organic Architectures That Have Improved Our Lives. J. Chem. Educ 2010, 53, 1348-1349.

(8). (a)For reviews involving transformations of $\mathrm{C}\left(\mathrm{sp}^{3}\right)-\mathrm{H}$ bonds, see: Dick AR; Sanford MS Transition metal catalyzed oxidative functionalization of carbon-hydrogen bonds. Tetrahedron 2006, 62, 2439-2463. ${ }^{3}$ (b)Daugulis O; Roane J; Tran LD Bidentate, monoanionic auxiliarydirected functionalization of carbon-hydrogen bonds. Acc. Chem. Res 2015, 48, 1053-1064. [PubMed: 25756616] (c)He J; Wasa M; Chan KSL; Shao Q; Yu J-Q Palladium-catalyzed transformations of alkyl C-H bonds. Chem. Rev 2017, 117, 8754-8786. [PubMed: 28697604] (d)Chu JCK; Rovis T Complementary strategies for directed $\mathrm{C}\left(\mathrm{sp}^{3}\right)-\mathrm{H}$ functionalization: A comparison of transition-metal-catalyzed activation, hydrogen atom transfer, and carbine/nitrene transfer. Angew. Chem., Int. Ed 2018, 57, 62-101.(e)He C; Whitehurst WG; Gaunt MJ Palladium-Catalyzed C $\left(\mathrm{sp}^{3}\right)-\mathrm{H}$ Bond Functionalization of Aliphatic Amines. Chem 2019, 5, 1031-1058.

(9) (a). Yu P; Zheng S-C; Yang N-Y; Tan B; Liu X-Y Phosphine-catalyzed remote $\beta$-C-H functionalization of amines triggered by trifluoromethylation of alkenes: One-pot synthesis of bistrifluoromethylated enamides and oxazoles. Angew. Chem., Int. Ed 2015, 54, 4041-4045. (b)Ma L; Paul A; Breugst M; Seidel D Redox-neutral aromatization of cyclic amines: Mechanistic insights and harnessing of reactive intermediates for amine $a$ - and $\beta-\mathrm{C}-\mathrm{H}$ functionalization. Chem. Eur. J 2016, 22, 18179-18189. [PubMed: 27712000]

(10). (a)For reviews of frustrated Lewis pair chemistry, see: Frustrated Lewis Pairs I: Uncovering and Understanding; Stephan DW; Erker G Eds.; Springer: Berlin, 2013; Vol. 332.(b)Frustrated Lewis Pairs II: Expanding the Scope; Erker G; Stephan DW Eds.; Springer: Berlin, 2013; Vol. 334. (c)Ashley AE; O'Hare D FLP-mediated activations and reductions of $\mathrm{CO}_{2}$ and CO. Top. Curr. Chem 2013, 334, 191-218. [PubMed: 23114497] (d)Feng X; Du H Metal-free asymmetric hydrogenation and hydrosilylation catalyzed by frustrated Lewis pairs. Tetrahedron Lett. 2014, 55, 6959-6964.(e)Stephan DW; Erker G Frustrated Lewis pair chemistry: Development and perspectives. Angew. Chem., Int. Ed 2015, 54, 6400-6441.(f)Stephan DW Frustrated Lewis pairs. J. Am. Chem. Soc 2015, 137, 10018-10032. [PubMed: 26214241] (g)Oestreich M; Hermeke J; Mohr J A unified survey of Si-H and $\mathrm{H}-\mathrm{H}$ bond activation catalysed by electron-deficient 
boranes. Chem. Soc. Rev 2015, 44, 2202-2220. [PubMed: 25679769] (h)Stephan DW The broadening reach of frustrated Lewis pair chemistry. Science 2016, 354, aaf7229. [PubMed: 27940818]

(11). (a)For selected reviews on cooperative catalysis, see: Tian S-K; Chen Y; Hang J; Tang L; McDaid P; Deng Li. Asymmetric Organic Catalysis with Modified Cinchona Alkaloids. Acc. Chem. Res 2004, 37, 621-631. [PubMed: 15311961] (b)Shibasaki M; Kumagai N in Cooperative Catalysis: Designing Efficient Catalysts for Synthesis, Peters R, Eds.; Wiley-VCH: New York, 2015; Chapter 1.

(12). (a)For selected reviews on enantioselective non-covalent catalysis, see: Phipps RJ; Hamilton GL; Toste FD The progression of chiral anions from concepts to applications in asymmetric catalysis. Nat. Chem 2012, 4, 603-614. [PubMed: 22824891] (b)Brak K; Jacobsen EN Asymmetric IonPairing Catalysis. Angew. Chem., Int. Ed 2013, 52, 534-561.(c)Neel AJ; Hilton MJ; Sigman MS; Toste FD Exploiting non-covalent $\pi$ interactions for catalyst design. Nature 2017, 543, 637-646. [PubMed: 28358089]

(13) (a). Millot N; Santini CC; Fenet B; Basset JM Formation and characterization of zwitterionic stereoisomers from the reaction of $\mathrm{B}\left(\mathrm{C}_{6} \mathrm{~F}_{5}\right)_{3}$ and $\mathrm{NEt}_{2} \mathrm{Ph}:(E)$ - and $(Z)-\left[\mathrm{EtPhN}^{+}=\mathrm{CHCH}_{2}-\mathrm{B}^{-}\right.$ $\left(\mathrm{C}_{6} \mathrm{~F}_{5}\right)_{3}$ ]. Eur. J. Inorg. Chem 2002, 2002, 3328-3335.(b)Dureen MA; Brown CC; Stephan DW Addition of enamines or pyrroles and $\mathrm{B}\left(\mathrm{C}_{6} \mathrm{~F}_{5}\right)_{3}$ "Frustrated Lewis Pairs" to alkynes. Organometallics 2010, 29, 6422-6432.(c)Farrell JM; Heiden ZM; Stephan DW Metal-Free Transfer Hydrogenation Catalysis by $\mathrm{B}\left(\mathrm{C}_{6} \mathrm{~F}_{5}\right)_{3}$. Organometallics 2011, 30, 4497-4500.

(14). Focante F; Mercandelli P; Sironi A; Resconi L Complexes of tris(pentafluorophenyl)boron with nitrogen-containing compounds: Synthesis, reactivity and metallocene activation. Coord. Chem. Rev 2006, 250, 170-188.

(15) (a). Zhang J; Park S; Chang S Catalytic access to bridged sila- $N$-heterocycles from piperidines via cascade $\mathrm{sp}^{3}$ and $\mathrm{sp}^{2} \mathrm{C}-\mathrm{Si}$ bond formation. J. Am. Chem. Soc 2018, 140, 13209-13213. [PubMed: 30269485] (b)Li R; Chen Y; Jiang K; Wang F; Lu C; Nie J; Chen Z; Yang G; Chen Y$\mathrm{C}$; Zhao Y; Ma C B $\left(\mathrm{C}_{6} \mathrm{~F}_{5}\right)_{3}$-catalyzed redox-neutral $\beta$-alkylation of tertiary amines using $p$ quinone methides via borrowing hydrogen. Chem. Commun 2019, 55, 1217-1220.

(16) (a). Maier AFG; Tussing S; Schneider T; Flörke U; Qu Z-W; Grimme S; Paradies J Frustrated Lewis pair catalyzed dehydrogenative oxidation of indolines and other heterocycles. Angew. Chem., Int. Ed 2016, 55, 12219-12223.(b)Kojima M; Kanai M Tris(pentafluorophenyl)boranecatalyzed acceptorless dehydrogenation of $N$-heterocycles. Angew. Chem., Int. Ed 2016, 55, 12224-12227.

(17) (a). Schwendemann S; Fröhlich R; Kehr G; Erker G Intramolecular frustrated N/B Lewis pairs by enamine hydroboration. Chem. Sci 2011, 2, 1842-1849.(b)Chen G-Q; Kehr G; Daniliuc CG; Bursch M; Grimme S; Erker G Intermolecular Redox-Neutral Amine C-H Functionalization Induced by the Strong Boron Lewis Acid $\mathrm{B}\left(\mathrm{C}_{6} \mathrm{~F}_{5}\right)_{3}$ in the Frustrated Lewis Pair Regime. Chem. Eur. J 2017, 23, 4723-4729. [PubMed: 28164392]

(18). Shang M; Chan JZ; Cao M; Chang Y; Wang Q; Cook B; Torker S; Wasa M C-H Functionalization of amines via alkene-derived nucleophiles through cooperative action of chiral and achiral Lewis acid catalysts: Applications in enantioselective synthesis. J. Am. Chem. Soc 2018, 140, 10593-10601. [PubMed: 30045617]

(19). Tian J-J; Zeng N-N; Liu N; Tu X-S; Wang X-C Intramolecular cyclizations of vinyl-substituted $N, N$-dialkyl arylamines enabled by borane-assisted hydride transfer. ACS Catalysis 2019, 9, 295300.

(20). (a)For $\mathrm{B}\left(\mathrm{C}_{6} \mathrm{~F}_{5}\right)_{3}$ and $N$-alkylamine-catalyzed deprotonation of carbonyl compounds, see: Shang M; Wang X; Koo SM; Youn J; Chan JZ; Yao W; Hastings BT; Wasa M Frustrated Lewis acid/ Brønsted base catalysts for direct enantioselective $a$-amination of carbonyl compounds. J. Am. Chem. Soc 2017, 139, 95-98. [PubMed: 27983825] 653(b)Cao M; Yesilcimen A; Wasa M Enantioselective Conia-Ene-Type Cyclizations of Alkynyl Ketones through Cooperative Action of $\mathrm{B}\left(\mathrm{C}_{6} \mathrm{~F}_{5}\right)_{3}, \mathrm{~N}$-Alkylamine and a Zn-Based Catalyst. J. Am. Chem. Soc 2019, 141, 4199-4203. [PubMed: 30786707] 
A: $\alpha, \beta$-Deuteration of bioactive compounds by Ru-based Shvo catalyst

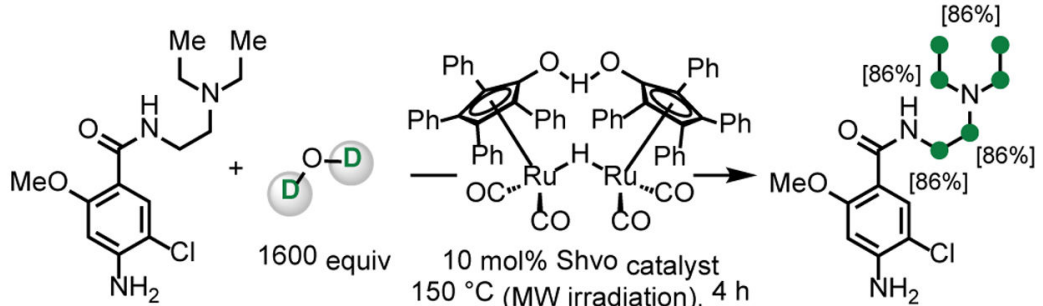

A1, metoclopramide

A2, $83 \%$ yield

B: Deuteration and tritiation of $\alpha$-amino $\mathbf{C}-\mathrm{H}$ bonds by photoredox catalysts<smiles></smiles>

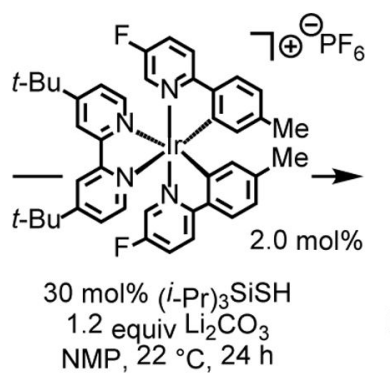

B1, (+)-cis-Diltiazem photoreactor

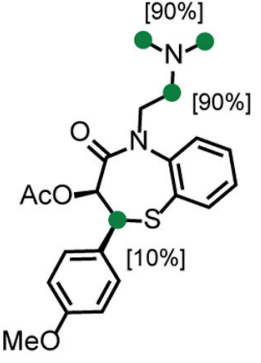

B2, $84 \%$ yield

C: Cooperative acid/base catalysts for deuteration of $\beta$-amino $\mathbf{C}-\mathrm{H}$ bonds (this work)

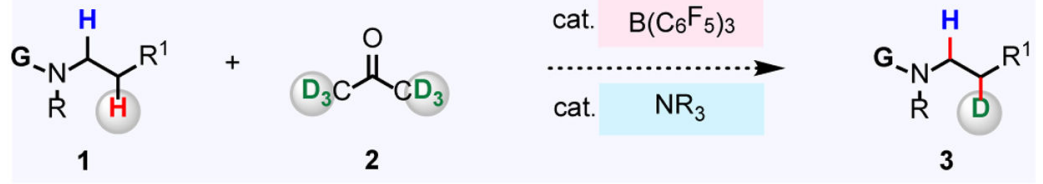

Proposed catalytic cycle:

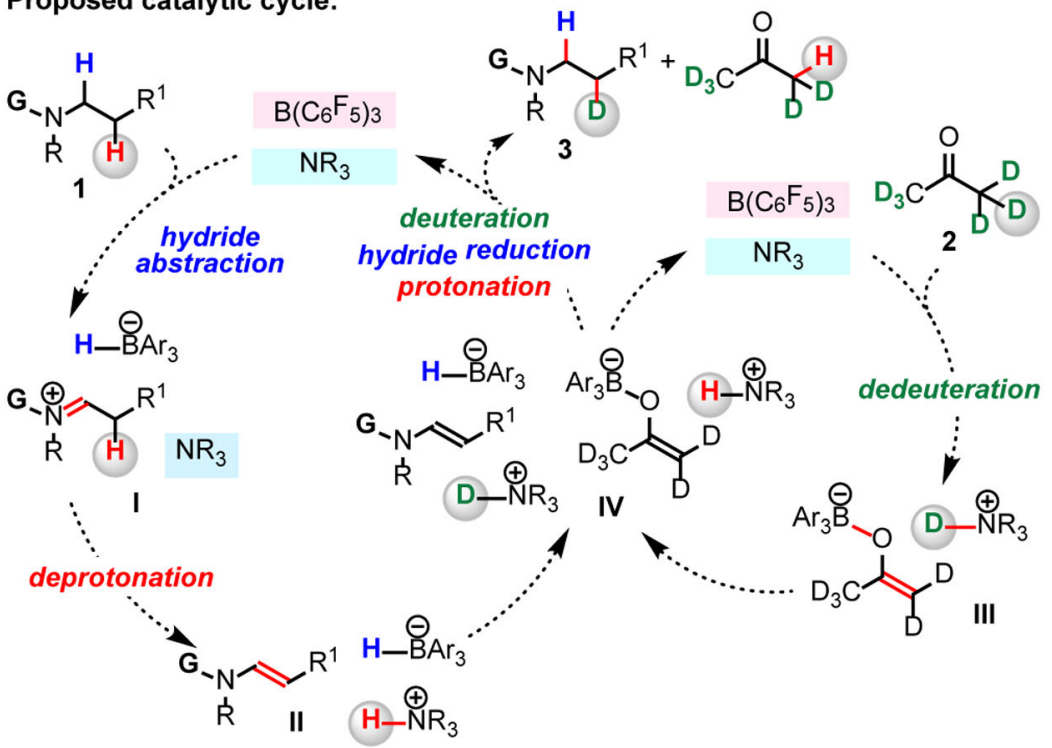

Figure 1.

Amino $\mathrm{C}-\mathrm{H}$ deuteration of biologically active molecules. 


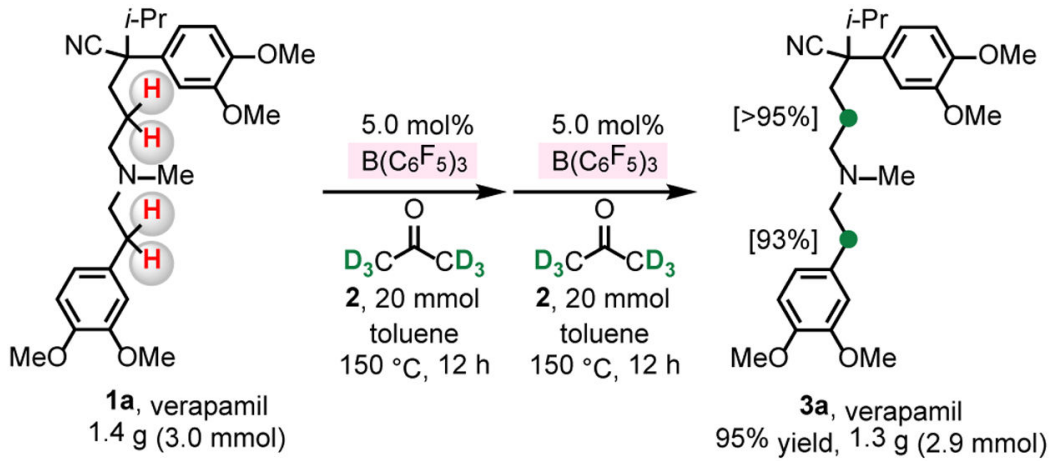

Scheme 1.

Scale-up experiment 
Table 1.

Evaluation of Reaction Parameters ${ }^{a, b, c, d}$

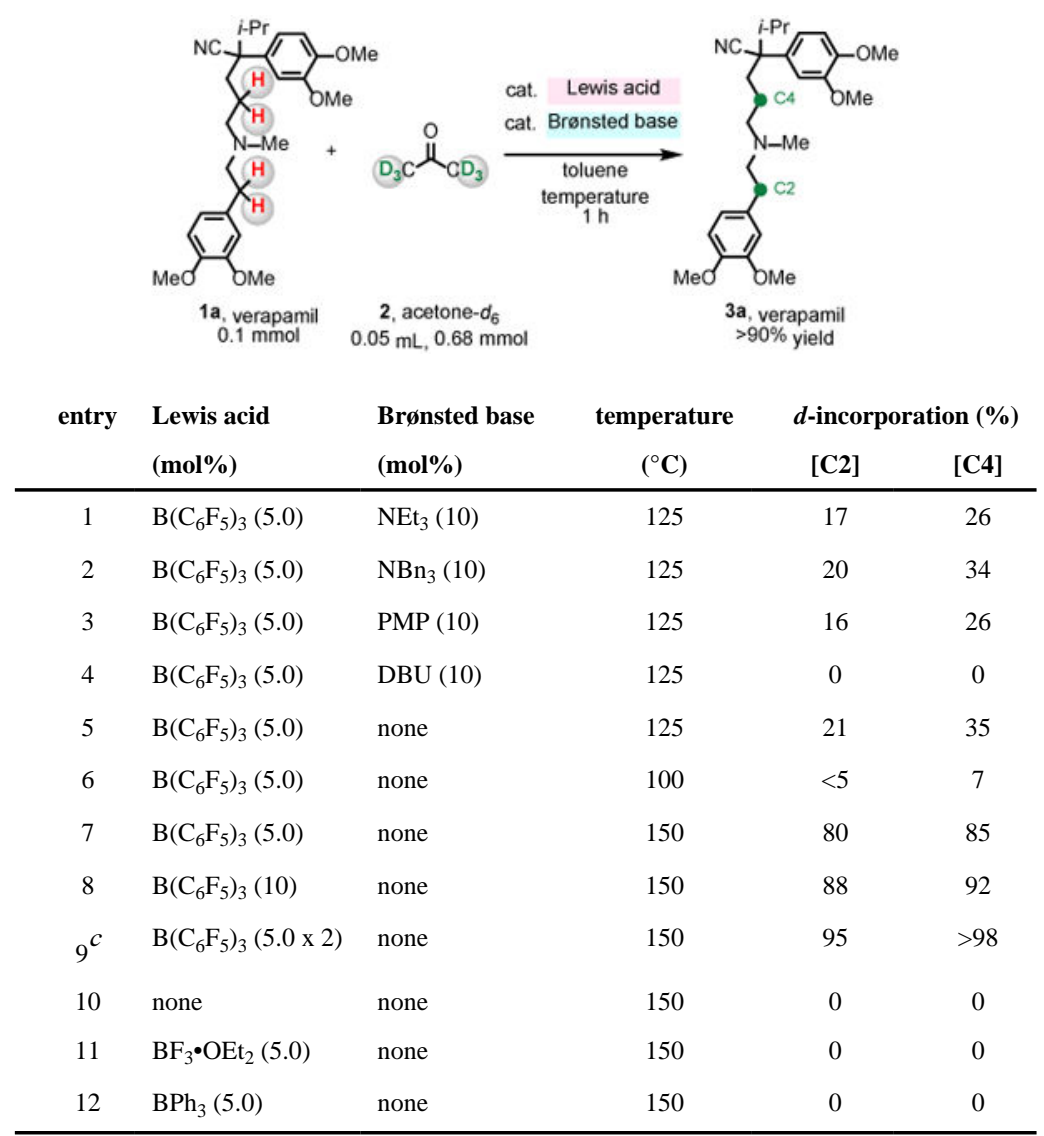

\footnotetext{
${ }^{a}$ Conditions: verapamil (1a, $\left.0.1 \mathrm{mmol}\right)$, acetone- $d_{6}(\mathbf{2}, 0.68 \mathrm{mmol})$, organoborane, Brønsted base, toluene $(0.4 \mathrm{~mL})$, under $\mathrm{N}_{2}, 1 \mathrm{~h}$.

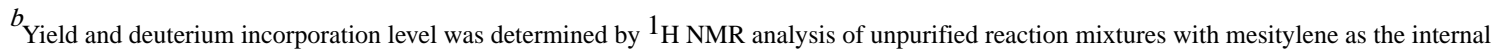
standard.

${ }^{c}$ Conditions: verapamil (1a, $\left.0.2 \mathrm{mmol}\right)$, acetone- $d_{6}(2,1.4 \mathrm{mmol}), \mathrm{B}\left(\mathrm{C}_{6} \mathrm{~F}_{5}\right) 3(5.0 \mathrm{~mol} \%)$, toluene $(0.8 \mathrm{~mL})$, under $\mathrm{N}_{2}, 150{ }^{\circ} \mathrm{C}, 1 \mathrm{~h}$. Isolated and purified 3a was reacted with acetone- $d_{6}(2,1.4 \mathrm{mmol}), \mathrm{B}\left(\mathrm{C}_{6} \mathrm{~F}_{5}\right) 3(5.0 \mathrm{~mol} \%)$, toluene $(0.8 \mathrm{~mL})$, under $\mathrm{N}_{2}, 150{ }^{\circ} \mathrm{C}, 1 \mathrm{~h}$.

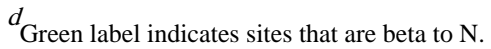


Table 2.

Deuteration of Acyclic $\beta$-Amino C-H Bonds ${ }^{a, b, c}$

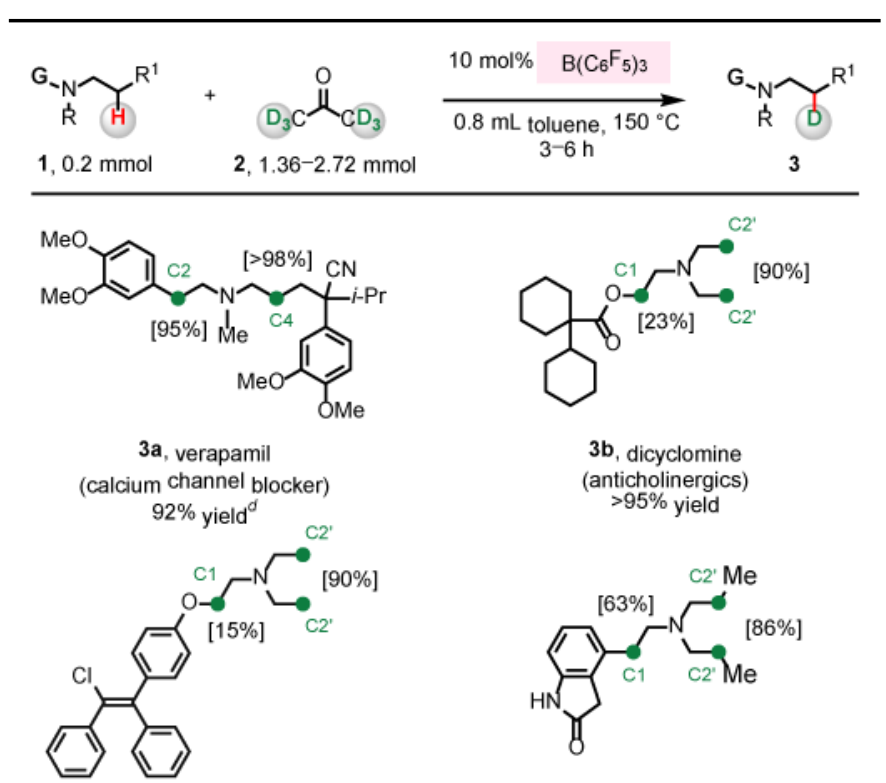

3c, clomiphene (ovulatory stimulant) $>95 \%$ yield

3d, ropinirole (Parkinson's disease)

$77 \%$ yield $^{e}$

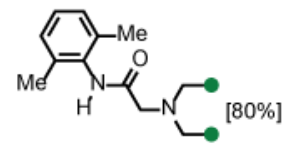

3e, lidocaine (local anesthetic) $>95 \%$ yield

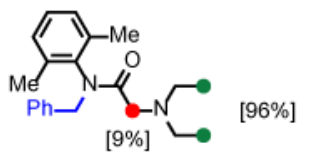

3f, $\mathrm{N}$-Bn lidocaine (local anesthetic) $>95 \%$ yield $^{d}$

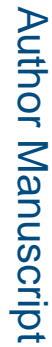

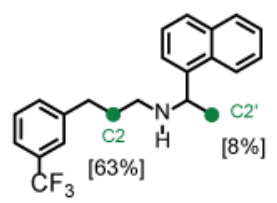

3g, cinacalcet (calcimimetic) $>95 \%$ yield

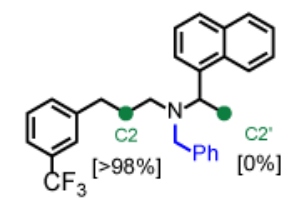

$3 \mathrm{~h}, \mathrm{~N}$-Bn cinacalcet (calcimimetic) $>95 \%$ yield $^{d}$
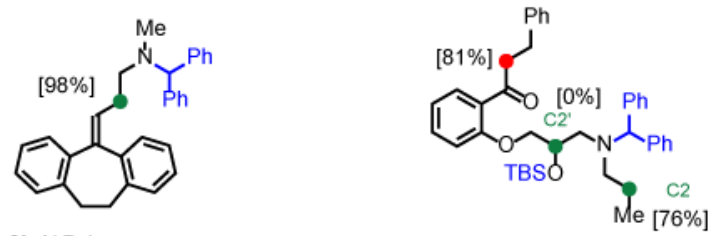

3i, N-Bzh nortriptyline (antidepressant) $>95 \%$ yield $^{d}$

3j, N-Bzh, O-TBS propafenone (antiarrhythmic agent)
$92 \%$ yield

${ }^{a}$ Conditions: $N$-alkylamine $(\mathbf{1}, 0.2 \mathrm{mmol})$, acetone- $d_{6}(\mathbf{2}, 1.36 \mathrm{mmol}), \mathrm{B}\left(\mathrm{C}_{6} \mathrm{~F}_{5}\right) 3(10 \mathrm{~mol} \%)$, toluene $(0.8 \mathrm{~mL})$, under $\mathrm{N}_{2}, 150{ }^{\circ} \mathrm{C}, 3 \mathrm{~h}$.

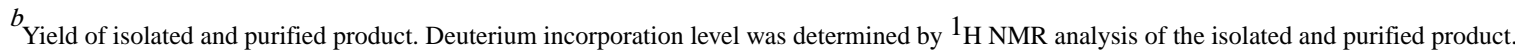

${ }^{c}$ Green label indicates sites that are beta to N. Red label is used for any other sites that undergo deuteration.

J Am Chem Soc. Author manuscript; available in PMC 2020 April 03. 
${ }^{d}$ Conditions: $N$-alkylamine $(\mathbf{1}, 0.2 \mathrm{mmol})$, acetone- $d_{6}(\mathbf{2}, 1.4 \mathrm{mmol}), \mathrm{B}\left(\mathrm{C}_{6} \mathrm{~F}_{5}\right) 3(5.0 \mathrm{~mol} \%)$, toluene $(0.8 \mathrm{~mL})$, under $\mathrm{N}_{2}, 150{ }^{\circ} \mathrm{C}, 3 \mathrm{~h}$. After the filtration of the crude reaction mixture through a pad of silica gel and removal of volatiles, acetone- $d_{6}(2,1.4 \mathrm{mmol}), \mathrm{B}\left(\mathrm{C}_{6} \mathrm{~F}_{5}\right) 3(5.0 \mathrm{~mol} \%)$, and toluene $(1.0 \mathrm{~mL})$ were added under $\mathrm{N}_{2}$, and then heated at $150{ }^{\circ} \mathrm{C}, 3 \mathrm{~h}$.

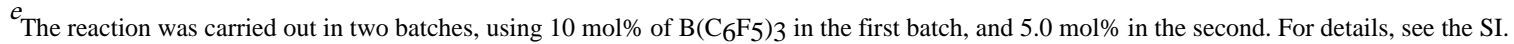


Table 3.

Deuteration of Cyclic Amino C-H Bonds ${ }^{a, b}$

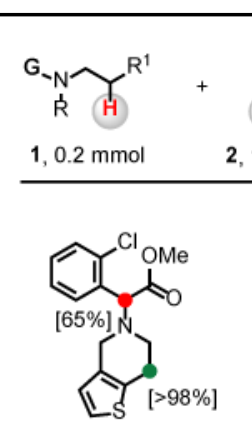

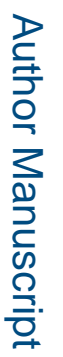
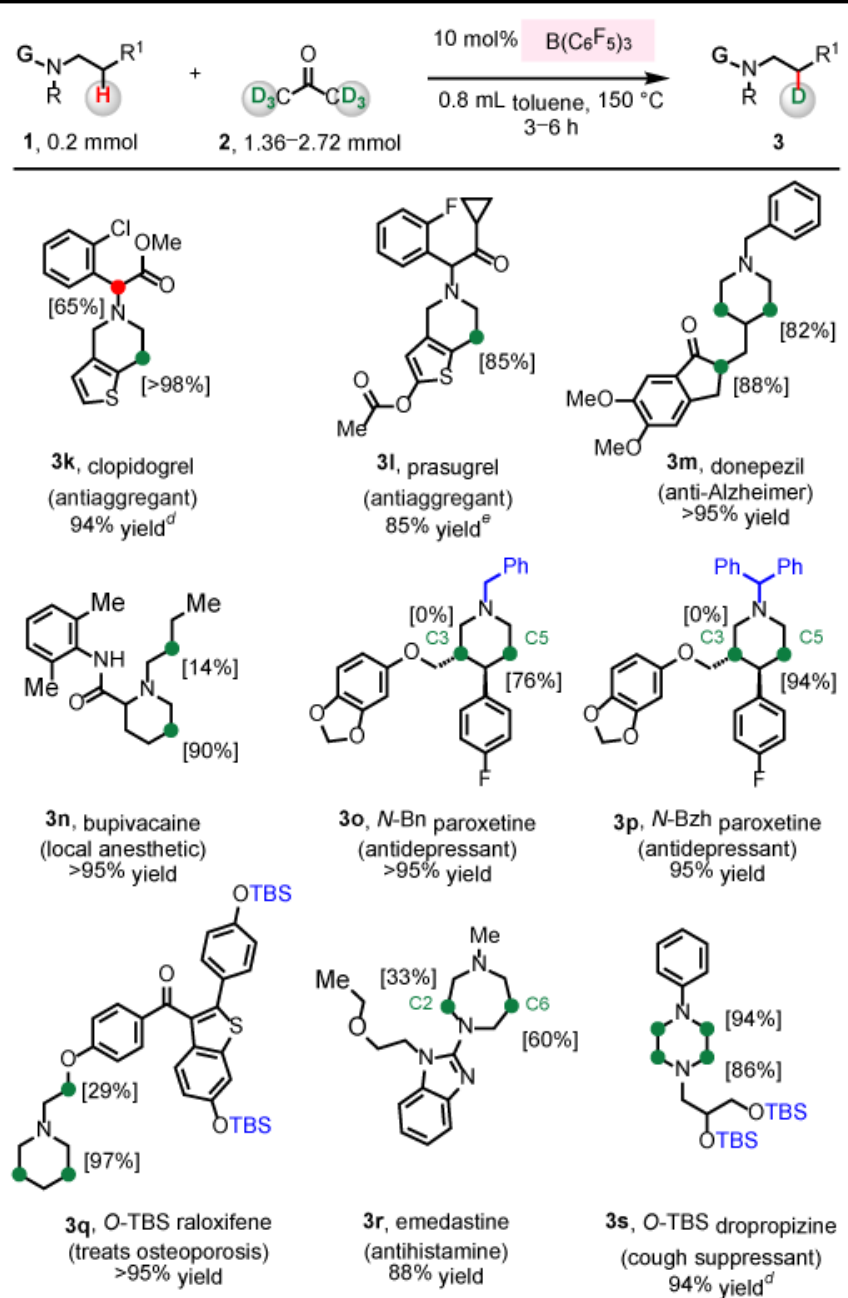
(antidepressant)
$>95 \%$ yield

3p, N-Bzh paroxetine (antidepressant)
$95 \%$ yield
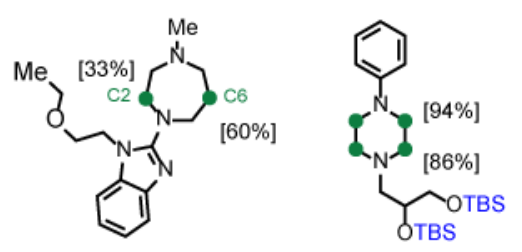

$3 r$, emedastine (antihistamine) $88 \%$ yield

3s, O-TBS dropropizine
(cough suppressant) $94 \%$ yield $^{d}$

${ }^{a}$ Conditions: $N$-alkylamine $(\mathbf{1}, 0.2 \mathrm{mmol})$, acetone- $d_{6}(\mathbf{2}, 1.36 \mathrm{mmol}), \mathrm{B}\left(\mathrm{C}_{6} \mathrm{~F}_{5}\right) 3(10 \mathrm{~mol} \%)$, toluene $(0.8 \mathrm{~mL})$, under $\mathrm{N}_{2}, 150{ }^{\circ} \mathrm{C}, 3 \mathrm{~h}$.

${ }^{b}$ Yield of isolated and purified product. Deuterium incorporation level was determined by ${ }^{1} \mathrm{H}$ NMR analysis of the isolated and purified product.

${ }^{c}$ Green label indicates sites that are beta to N. Red label is used for any other sites that undergo deuteration.

${ }^{d}$ Conditions: $N$-alkylamine $(1,0.2 \mathrm{mmol})$, acetone- $d_{6}(2,1.4 \mathrm{mmol}), \mathrm{B}\left(\mathrm{C}_{6} \mathrm{~F}_{5}\right) 3(5.0 \mathrm{~mol} \%)$, toluene $(0.8 \mathrm{~mL})$, under $\mathrm{N}_{2}, 150^{\circ} \mathrm{C}, 3 \mathrm{~h}$. After the filtration of the crude reaction mixture through a pad of silica gel and removal of volatiles, acetone- $d 6(2,1.4 \mathrm{mmol}), \mathrm{B}\left(\mathrm{C}_{6} \mathrm{~F}_{5}\right) 3(5.0 \mathrm{~mol} \%)$, and toluene $(1.0 \mathrm{~mL})$ were added under $\mathrm{N}_{2}$, and then heated at $150{ }^{\circ} \mathrm{C}, 3 \mathrm{~h}$.

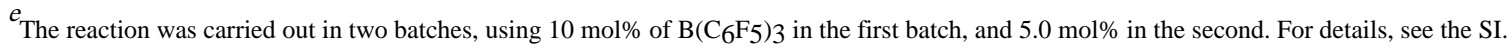

